\title{
Replacement of the Octadecenoic Acid Growth-requirement for Acholeplasma laidlawii A by cis-9,10-Methylenehexadecanoic Acid, a Cyclopropane Fatty Acid
}

\author{
By C. PANOS AND OFRA LEON \\ Department of Microbiology, Jefferson Medical College of Thomas Jefferson University, \\ Philadelphia, Pennsylvania, U.S.A.
}

(Received 25 April 1973; revised I 2 July 1973)

SUMMARY

The octadecenoic acid growth-requirement for Acholeplasma (Mycoplasma) laidlawii A can be effectively replaced by cis-9, I0-methylenehexadecanoic acid but not by cis-9,10-hexadecenoic acid. Once incorporated into the membrane polar lipids, this acid is also elongated to cis-I I, I 2-methyleneoctadecanoic acid. This is the first instance of the elongation of a cyclopropane fatty acid by a microorganism. cis-9,10-Methylenehexadecanoic acid, like cis-9, I0-octadecenoic acid, alters the osmotic fragility of this mycoplasma, but while a correlation exists between fatty acid concentration and yield of organism, there is no apparent relationship between fatty acid concentration, maximal yield and greatest membrane osmotic stability for this organism. The fatty acid composition of the membrane polar lipids of $A$. laidlawii A grown with cis-I I, I2-octadecenoic and cis-9,10-methylenehexadecanoic acids shows each acid to be incorporated to a similar extent. A cell-free system from $A$. laidlawii A synthesized less cis-I I, I 2methyleneoctadecanoic and tetradecanoic acids but more octadecanoic acid when compared with the fatty acid composition of the intact organism.

\section{INTRODUCTION}

Extensive studies from these laboratories on the composition, biosynthesis and interconversion of fatty acids in various saprophytic mycoplasmas have appeared (Henrikson \& Panos, I969; Panos \& Henrikson, I969; Rottem \& Panos, I969; Panos \& Rottem, I970; Rottem \& Panos, 1970). For example, Acholeplasma (formerly Mycoplasma) laidlawii strain A, but not strain B, requires an exogenous octadecenoic acid for growth (Panos \& Rottem, 1970). cis-9,10-Hexadecenoic acid cannot replace this need, as enzymes necessary for the elongation of hexadecenoic acids to octadecenoic acids are absent (Rottem \& Panos, 1970). Cyclopropane fatty acids are not found in mycoplasmas, including $A$. laidlawii A (Henrikson \& Panos, I969; Panos \& Henrikson, I969; Rottem \& Panos, I969; Panos \& Rottem, I970) but cis-I I, I 2-methyleneoctadecanoic (lactobacillic) acid and cis-9,10methyleneoctadecanoic (dihydrosterculic) acid can replace the octadecenoic acid growthrequirement for A. laidlawii A (Rottem \& Panos, 1969; Panos \& Rottem, 1970). Also, high concentrations of cyclopropane fatty acids in the growth medium are as effective as cisoctadecenoic acids in increasing the resistance of this mycoplasma to osmotic lysis (Rottem \& Panos, 1969).

At present, no information is available on the utilization of cyclopropane fatty acids with less than I9 carbon atoms by a mycoplasma. This study details the ability of cis-9, I0- 
methylenehexadecanoic acid to replace the octadecenoic acid growth-requirement for Acholeplasma laidlawii A. Also, the incorporation of this unusual fatty acid into the membrane polar lipids of this organism and its continued elongation and ability 10 alter the osmotic fragility of the membrane are examined.

\section{METHODS}

Organism and growth conditions. Acholeplasma (formerly Mycoplasma) laidlawii a (oral strain), the same as used previously (Rottem \& Panos, I969; Panos \& Rottem, 1970), was grown in $5 \mathrm{l}$ of medium as previously described (Panos \& Rottem, 1970). Fatty acids were added to sterile medium as ethanolic solutions, the final concentration of ethanol not exceeding 0.1 to $0.2 \%$ of the growth medium. The residual fatty acid content of the tryptosealbumin ingredients of the growth medium was $0.0059 \%$ and its composition has been detailed (Rottem \& Panos, 1969). A. laidlawii A was harvested during its logarithmic growth phase, after 24 and $36 \mathrm{~h}$ incubation $\left(37^{\circ} \mathrm{C}\right)$ with cis- I I, I 2-octadecenoic acid and the cyclopropane fatty acids, respectively. Growth was determined from the extinction at $400 \mathrm{~nm}$ as before (Rottem \& Panos, 1969). After centrifuging at $17000 \mathrm{~g}$ for $20 \mathrm{~min}$, the organism was washed once with $0.25 \mathrm{M}-\mathrm{NaCl}$ and the amount of protein determined according to Lowry, Rosebrough, Farr \& Randall (1951). Lyophilized membranes from A. laidlawii A were obtained by osmotic lysis as described elsewhere (Razin, Tourtellotte, McElhaney \& Pollack, I966; Panos \& Rottem, i970).

For cell-free studies, Acholeplasma laidlawii A was grown as above and extracts prepared as has been detailed (Rottem \& Panos, 1970).

Lipid extraction and chromatography. Lyophilized membranes were extracted with chloroform + methanol $(2: \mathrm{I}, \mathrm{v} / \mathrm{v})$ and the glycolipids and phospholipids obtained by silicic acid column chromatography as described elsewhere (Cohen \& Panos, 1966). More than $88 \%$ of the total lipids extracted were recovered after column chromatography. Glycolipid and phospholipid column chromatographic fractions were chromatogrammed on thin layers of silica gel $\mathrm{G}(0.5 \mathrm{~mm}$ thick) using, respectively, chloroform + methanol $(8: 2, \mathrm{v} / \mathrm{v})$ and chloroform + methanol + water $(65: 25: 4$, by vol.) as solvent systems. All plates were sprayed with $0.2 \%$ ninhydrin in acetone, a reagent to detect phosphorus (Dittmer \& Lester, 1964) and rhodamine $6 \mathrm{G}(0.01 \%)$.

Analysis of fatty acids. The alkaline hydrolysis-fatty acid extraction method of Hofmann, Henis \& Panos ( 1957), modified by the omission of bicarbonate washings, was used throughout. As cyclopropane acids may be degraded upon esterification with $\mathrm{BF}_{3}$ in methanol (Dawidowicz \& Thompson, 1971; Goldfine \& Panos, 1971; Brian, Gracy \& Scholes, 1972) all methylations were done by the diazomethane or perchloric acid procedures which gave consistent quantitative recoveries of cis-9, I O-methylenehexadecanoic and cis-1 I, 1 2-methyleneoctadecanoic acids. Esterified fatty acid mixtures were resolved by gas chromatography using a capillary column $40.6 \mathrm{~m} \times 0.25 \mathrm{~mm}$ newly coated with Carbowax K-20 M+V-93 $(99+1)$ (Perkin-Elmer Corp., Norwalk, Connecticut, U.S.A.) (Panos, Cohen \& Fagan, I 966). Mild and catalytic hydrogenation of fatty acid samples (Panos et al. I966; Weinbaum \& Panos, I966) and infra-red analyses (Rottem \& Panos, 1969) were also performed.

Cell-free system. Saturated fatty acid synthesis and cyclopropane fatty acid elongation were studied using an extract of Acholeplasma laidlawii A, obtained as above, and reaction mixtures containing $\left[2-{ }^{14} \mathrm{C}\right]$-malonyl-CoA (Rottem \& Panos, 1970). The saturated fatty acid mixture used as carrier for the collection of each labelled fatty acid contained tetradecanoic, hexadecanoic, cis-9, I0-methylenehexadecanoic, octadecanoic, nonadecanoic, 


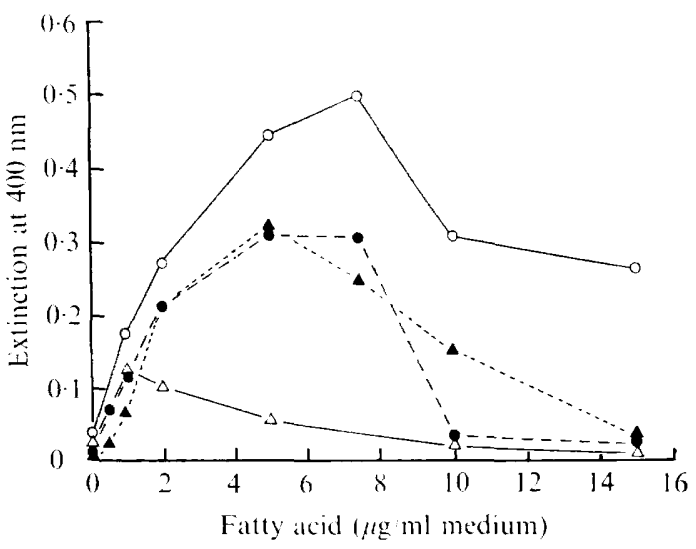

Fig. I. The effect of monoenoic and cyclopropane fatty acids on growth of Acholeplasma laidlawii A in a lipid pre-extracted medium. $O$, cis-1 I, 12-Octadecenoic acid; $\Delta$, cis-9, 10-hexadecenoic acid;

-, cis-9, I0-methylenehexadecanoic acid; $\boldsymbol{\Delta}$, cis-11, I 2-methyleneoctadecanoic acid.

cis-I I, I 2-methyleneoctadecanoic, eicosanoic, heneicosanoic and docosanoic acids. Radioactivity was assayed by liquid scintillation.

Osmotic fragility and plate counts. Spectrophotometric assessment of osmotic fragility and determination of colony-forming units $/ \mathrm{ml}$ of medium are detailed elsewhere (Rottem \& Panos, 1969).

Chemicals. cis-I I, I2-Methyleneoctadecanoic acid was a gift from Dr Klaus Hofmann, Protein Research Laboratories, University of Pittsburg, Pittsburgh, Pennsylvania, U.S.A. cis-9,10-Methylenehexadecanoic acid was obtained by vacuum fractional distillation of methylated fatty acids (Hofmann, Lucas \& Sax, 1952) derived from Escherichia coli and, following partial purification by preparative polar-column gas chromatography (Rottem \& Panos, 1970) and removal of column substrate by silicic-acid column chromatography, it was finally purified by thin-layer chromatography on silica gel $\mathrm{G}$ plates containing $\mathrm{AgNO}_{3}$ $(15 \%, \mathrm{w} / \mathrm{v})$ and rhodamine $6 \mathrm{G}(0.01 \%, \mathrm{w} / \mathrm{v})$ as indicator. In a solvent system of petroleum ether (b.p. 30 to $60{ }^{\circ} \mathrm{C}$ ) + diethyl ether (99:I, v/v), esterified cis-9, Io-methylenehexadecanoic acid had an $R_{F}$ of 0.50 . Purity was confirmed by capillary column gas chromatography.

\section{RESULTS}

The optimal concentration of cis-9, I o-methylenehexadecanoic acid for growth of Acholeplasma laidlawii A was 5.0 to $7 \cdot 5 \mu \mathrm{g} / \mathrm{ml}$ (Fig. I). At $\mathrm{I} 0 \mu \mathrm{g} / \mathrm{ml}$ it had a toxic effect which was much greater than that of equal concentrations of cis-I I, I 2- and cis-9,10-methyleneoctadecanoic acids, the latter having been tested earlier (Rottem \& Panos, I969), and of cisI I, I 2-octadecenoic acid (Fig. I and Table I).

The yield of the organism when grown with cis-9,10-methylenehexadecanoic acid was considerably less than when grown with cis-I I, I 2-octadecenoic acid (Fig. I and Table I). Colony-forming units were also less with the former acid, but using fatty acid concentrations giving maximal growth $(7.5 \mu \mathrm{g} / \mathrm{ml}$, Fig. I) both acids decreased the osmotic fragility to a similar extent (Table I). cis-I I, I 2-Methyleneoctadecanoic acid (at $5 \mu \mathrm{g} / \mathrm{ml}$ ) failed to alter significantly the osmotic fragility of this organism ( $78 \%$ of control). The extinction (see Fig. I) and the colony-forming units/ml for Acholeplasma laidlawii A when grown with cis-I I,I 2- 
Table I. Comparison of cis-I I, I 2-octadecenoic and cis-9,10-methylenehexadecenoic acids on growth and osmotic fragility of Acholeplasma laidlawii $\mathrm{A}$

Organism grown in 'lipid-free' tryptose medium containing $0.25 \%$ charcoal-treated bovine serum albumin with fatty acids as indicated.

\begin{tabular}{|c|c|c|c|c|}
\hline \multirow[b]{2}{*}{$\begin{array}{l}\text { Fatty acid added to } \\
\text { growth medium }\end{array}$} & \multirow[b]{2}{*}{$\begin{array}{c}\text { Concentration } \\
\text { of fatty acid } \\
(\mu \mathrm{g} / \mathrm{ml})\end{array}$} & \multicolumn{2}{|c|}{ Yield of $A$. laidlawii } & \multirow[b]{2}{*}{$\begin{array}{l}\text { Osmotic } \\
\text { fragility* }\end{array}$} \\
\hline & & $\begin{array}{l}\text { (mg protein/ } \\
100 \mathrm{ml} \text { ) }\end{array}$ & $\begin{array}{l}\text { (Colony- } \\
\text { forming } \\
\text { units } / \mathrm{ml} \text { ) }\end{array}$ & \\
\hline$c i s-1$ I, I 2-Octadecenoic & $\begin{array}{r}5 \cdot 0 \\
7 \cdot 5 \\
10 \cdot 0\end{array}$ & $\begin{array}{l}4 \cdot 0 \\
4 \cdot 5 \\
3 \cdot 6\end{array}$ & $\begin{array}{l}5.4 \times 10^{10} \\
\text { N.D. } \\
2 \cdot 3 \times 10^{9}\end{array}$ & $\begin{array}{l}76 \\
57 \\
47\end{array}$ \\
\hline $\begin{array}{l}\text { cis-9,10-Methylene- } \\
\text { hexadecanoic }\end{array}$ & $\begin{array}{r}5 \cdot 0 \\
7 \cdot 5 \\
10 \cdot 0\end{array}$ & $\begin{array}{l}I \cdot 6 \\
I \cdot O \\
\text { N.D. }\end{array}$ & $\begin{array}{l}\text { I. } 9 \times 10^{9} \\
\text { N.D. } \\
5.2 \times 10^{8}\end{array}$ & $\begin{array}{l}66 \\
60 \\
\text { N.D. }\end{array}$ \\
\hline
\end{tabular}

* Percentage lysis in $0.05 \mathrm{M}-\mathrm{NaCl}(0.25 \mathrm{M}-\mathrm{NaCl}$ used as control). N.D., Not determined.

Table 2. Yields of lipids from membranes of Acholeplasma laidlawii a grown with cyclopropane fatty acids at $3 \mu \mathrm{g} / \mathrm{ml}$

Typical data from 20 l cultures harvested during logarithmic phase of growth. Lipids were fractionated by silicic-acid column chromatography.

$\begin{array}{lcc}\begin{array}{c}\text { cis-9, I0- } \\ \text { Methylene- } \\ \text { hexadecanoic }\end{array} & \begin{array}{c}\text { Methylene- } \\ \text { acid }\end{array} & \begin{array}{c}\text { Actadecanoic } \\ \text { acid }\end{array} \\ \text { Membranes (mg) } & 635.3 & 855.0 \\ \text { Total lipid (mg) } & 88.0 & 111.1 \\ \text { Non-polar lipid (\%) } & 6 \cdot 1 & 3.5 \\ \text { Monoglycolipid in lipid }(\%) & 25.6 & 28.8 \\ \text { Diglycolipid in lipid (\%) } & 16.5 & 17.6 \\ \text { Phospholipids in lipid }(\%) & 46.6 & 38.7\end{array}$

methyleneoctadecanoic or cis-9,10-methylenehexadecanoic acids at $5 \mu \mathrm{g} / \mathrm{ml}$ were similar $\left(\mathrm{I} \cdot 3 \times 10^{9}\right.$ and $1 \cdot 9 \times 10^{9}$, respectively).

The total lipid content of membranes from Acholeplasma laidlawii A, grown with either of two cyclopropane fatty acids of different chain lengths, remained constant (approximately $13 \%$ ), with the proportion of the monoglycoside component being always significantly greater than its homologous diglycoside component (ratio in excess of $\mathrm{I}: \mathrm{I} \cdot 5$, Table 2 ). Glycolipids and phospholipids comprised more than 42 and $38 \%$, respectively, of the total membrane polar lipids (see also Rottem \& Panos, 1969). Thin-layer chromatography indicated only 'one monoglycolipid $\left(R_{F} 0.78\right)$ and one diglycolipid $\left(R_{F} 0.57\right)$ in the column chromatographic fractions eluted with chloroform + acetone and acetone, respectively. At least four major phospholipids, however, were apparent from the fraction obtained with chloroform + methanol. No further characterization of these individual lipids was attempted since the complex lipids of the mycoplasmas have been detailed by Smith (1971) and by Razin (1 973).

Acholeplasma laidlawii A when grown with cis-II,I2-octadecenoic acid incorporated $78.8 \%$ of it into the membrane polar lipids, and after growth on cis-9,10-methylenehexa- 
Table 3. Fatty acid composition of membrane lipids of logarithmically growing Acholeplasma laidlawii A from 'lipid-free' growth medium containing octadecenoic and cyclopropane fatty acids

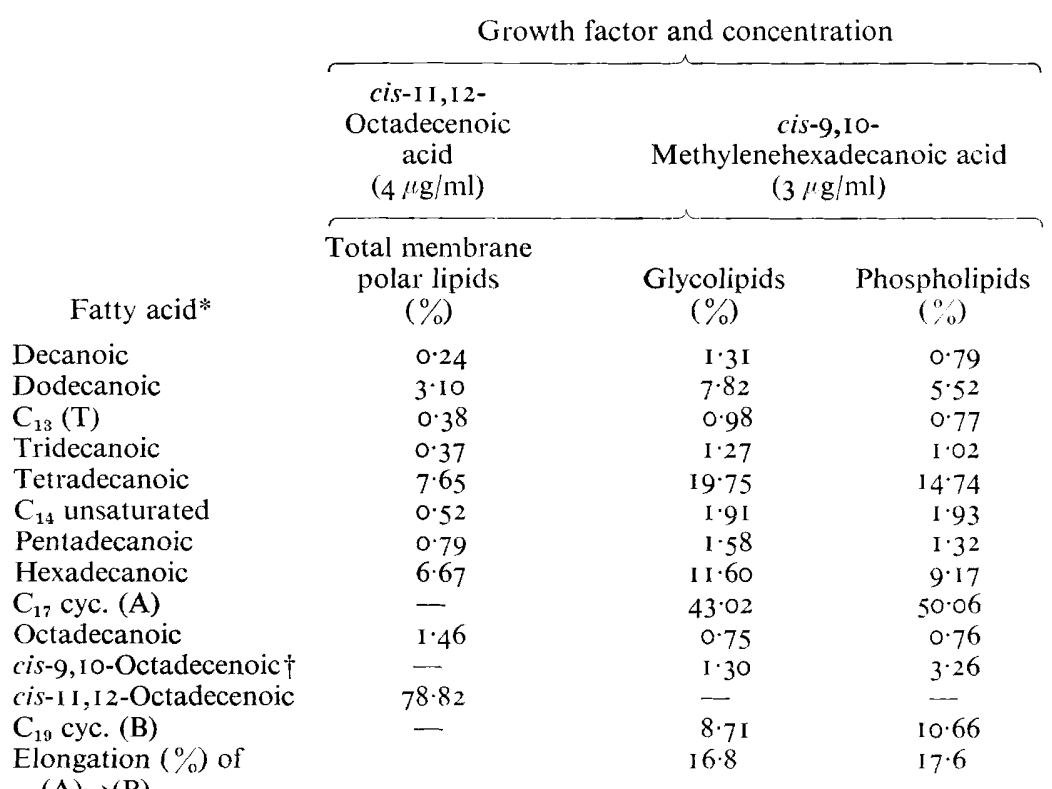

* Analyses by capillary column (polar) gas chromatography. $\mathrm{T}=$ tentative identification as branched methyl acids; numerals indicate total carbon atom content; $\mathrm{C}_{17}$ cyc., cis-9, $10-$ methylenehexadecanoic acid; $\mathrm{C}_{19}$ cyc., cis-1 I, 12-methyleneoctadecanoic acid.

$\dagger$ Contaminant of medium.

decanoic acid up to $60 \%$ of this acid was incorporated into the membrane glycolipids and phospholipids both as the unchanged acid and after elongation to cis-I I, I2-methyleneoctadecanoic acid (Table 3). Gas chromatography did not detect any further elongation. The concentrations of cis-II, I2-octadecenoic and cis-9, IO-methylenehexadecanoic acids used were a compromise between that permitting near optimal growth and that giving no toxicity (Fig. I). Confirmation of cis-I I, I 2-methyleneoctadecanoic acid formation was by co-chromatography with an authentic sample (see Panos \& Henrikson, 1968); by its persistence after mild hydrogenation ( $5 \%$ palladium on charcoal in methanol); and by its disappearance after catalytic hydrogenation (Adams catalyst and glacial acetic acid) which resulted in the concomitant appearances of the appropriate saturated, straight chain acid and methyl branched acids during capillary-column gas chromatography. Also, the characteristic infra-red band at $9.8 \mu \mathrm{m}$ for the cyclopropane ring could no longer be detected.

A small but consistently greater amount of cis-9,10-methylenehexadecanoic acid was always apparent in the phospholipids as compared with the glycolipids (Table 3), which was similar to the growth of Acholeplasma laidlawii A with cis-I I, I 2-octadecenoic acid (Rottem \& Panos, 1969). As in previous studies (Panos \& Rottem, 1970), short chain $\left(C_{14}\right.$ to $\left.C_{16}\right)$ unsaturated acids were absent from this organism when grown with cis-9, I0-methylenehexadecanoic acid. The greater amount of tetradecanoic acid versus hexadecanoic acid noted during logarithmic growth of this and other saprophytic mycoplasmas (Henrikson \& Panos, I969; Panos \& Henrikson, 1969; Rottem \& Panos, 1969; Panos \& Rottem, I970) was retained when $A$. laidlawii A was grown with cis-9, Io-methylenehexadecanoic acid. The 


\section{Table 4. Cyclopropane fatty acid elongation and saturated straight-chain fatty acid synthesis by a cell-free system of Acholeplasma laidlawii A}

Reaction mixture (in $\mu$ moles) : $\mathrm{C}_{17}$ or $\mathrm{C}_{19}$ cyclopropane acid substrate, 0.16 ; ATP, I ; NADPH, 0.5 ; $\mathrm{MgCl}_{2}, 5 ; 2$-mercaptoethanol, 5; triethanolamine- $\mathrm{HCl}$ buffer $(\mathrm{pH} 7 \cdot 4), 30 ;\left[2-{ }^{14} \mathrm{C}\right]$-malonyl-CoA, 150000 c.p.m.; and cell-free extract ( $2 \mathrm{mg}$ cell protein) from cells grown with either substrate. Total volume, $1 \mathrm{ml}$; temperature, $37^{\circ} \mathrm{C}$; time, $30 \mathrm{~min}$. Total ethanol concentration in reaction mixture, $0.06 \%(\mathrm{v} / \mathrm{v})$, for addition of substrates.

$\overbrace{\mathrm{C}_{19} \text { cyc. } \mathrm{C}_{17} \text { cyc. }}^{\begin{array}{c}\text { Percentage of } \\ \mathrm{C}_{17} \text { cyc. grown cells* }\end{array}}$ None

Fatty acid $\dagger$

Tetradecanoic

Hexadecanoic

$\mathrm{C}_{17}$ cyc.

Octadecanoic

Nonadecanoic

$\mathrm{C}_{19}$ cyc.

Eicosanoic

Heneicosanoic

$\mathrm{C}_{21}$ cyc.

Docosanoic

Beyond docosanoic +

$\begin{array}{rrr}\text { I.I } & 1.5 & 0.6 \\ 25.4 & 35.4 & 28.8 \\ 0.6 & \mathrm{I} \cdot \mathrm{I} & 0.0 \\ 6 \mathrm{I} \cdot \mathrm{2} & 5 \mathrm{I} \cdot 8 & 58 \cdot 8 \\ \mathrm{~N} . \mathrm{C} . & \mathrm{N} . \mathrm{C} . & \mathrm{N} . \mathrm{C} . \\ 0.7 & 3 \cdot \mathrm{I} & 2 \cdot \mathrm{I} \\ \mathrm{I} & & 9.2\end{array}$

\begin{tabular}{|c|c|}
\hline \multicolumn{2}{|c|}{ Substrate } \\
\hline $\mathrm{C}_{19}$ cyc. & None \\
\hline \multicolumn{2}{|c|}{$\begin{array}{c}\text { Percentage of } \\
\mathrm{C}_{19} \text { cyc. grown cells* }\end{array}$} \\
\hline N.C. & $I \cdot 6$ \\
\hline $29 \cdot 4$ & $25 \cdot 2$ \\
\hline N.C. & N.C. \\
\hline $57 \cdot 9$ & $62 \cdot 3$ \\
\hline $2 \cdot 8$ & $3 \cdot 5$ \\
\hline$I \cdot O$ & N.C. \\
\hline $4 \cdot 6$ & $2 \cdot 9$ \\
\hline $2 \cdot 9$ & $3 \cdot 6$ \\
\hline $0 \cdot 3$ & N.C. \\
\hline 0.5 & 0.7 \\
\hline 0.5 & N.C. \\
\hline
\end{tabular}

* Average total fatty acids formed per cell-free system $=3600$ to 4000 c.p.m. Fatty acids isolated by preparative column gas chromatography.

$+\mathrm{C}_{1} ;$ cyc. $=$ cis-9, 10 -methylenehexadecanoic acid; $\mathrm{C}_{19}$ cyc. = cis-I I, I2-methyleneoctadecanoic acid; $\mathrm{C}_{21}$ cyc. $=$ cyclopropane acid with $2 \mathrm{I}$ carbon atoms.

+ Fraction collected for $\mathrm{I} h$ after elution of docosanoic acid.

N.C., Not counted.

percentages of total fatty acids from lyophilized membranes of this organism grown with cis-I I,I2-octadecenoic acid and the $\mathrm{C}_{17}$ cyclopropane fatty acid were 20 and $13 \%$, respectively.

Cell-free extracts from Acholeplasma laidlawii a synthesized saturated fatty acids in the presence and absence of added cis-9,10-methylenehexadecanoic acid (Table 4 ). The continued formation of labelled cis-I I, I 2-methyleneoctadecanoic acid in the absence of added cis-9, 10-methylenehexadecanoic acid was probably due to residual amounts of the latter in extracts from this organism when grown with this $\mathrm{C}_{17}$ acid. Likewise, the inability of such extracts to form significant amounts of labelled cis-I I, I 2-methyleneoctadecanoic acid when unlabelled cis-I I, I 2-methyleneoctadecanoic acid was added to reaction mixtures probably reflects a feedback inhibition. Indeed, addition of $c i s$ - I I, I 2-methyleneoctadecanoic acid to such reaction mixtures resulted in the inhibition of cis-9, I0-methylenehexadecanoic acid elongation by approximately $66 \%(0 \cdot 7 / 2 \cdot \mathrm{I} \times \mathrm{I} 00)$. Extracts from $A$. laidlawii A grown with $c i s$-I I, I 2-methyleneoctadecanoic acid and then incubated with it as substrate always produced small amounts of radioactivity upon gas chromatography, having a relative retention time for a cyclopropane acid with $2 \mathrm{I}$ carbon atoms $(0.3 \%)$. Extensive elongation of lactobacillic acid therefore does not occur.

Also apparent was the low amount of tetradecanoic acid, the high concentration of octadecanoic acid and the decreased formation of cis-I I, I 2-methyleneoctadecanoic acid by the cell-free system as compared with the intact organism. Some formation of heneicosanoic and docosanoic acids was noted only with the cell-free system (Tables 3 and 4). 


\section{DISCUSSION}

The elongation of cis-9, I -methylenehexadecanoic acid to cis-I I, I 2-methyleneoctadecanoic acid by Acholeplasma laidlawii A is of interest because the Mycoplasmatales are apparently devoid of these cyclopropane fatty acids (Henrikson \& Panos, 1969; Panos \& Henrikson, I969; Rottem \& Panos, 1969; Panos \& Rottem, 1970; Smith, 1971). This elongation does not occur in bacteria which synthesize those fatty acids by adding a methylene group to either octadecenoic acid or hexadecenoic acid (Hofmann, 1962; O'Leary, 1967). To our knowledge, this is the first detection of the elongation of a cyclopropane fatty acid by a micro-organism. However, only a relatively small amount of cis-1 I, I 2-methyleneoctadecanoic acid is formed from cis-9, I0-methylenehexadecanoic acid, which suggests that both acids, individually, can replace the octadecenoic acid growth-requirement of $A$. laidlawii A (see Fig. I). While others (see Razin, 1973) have reported changes in the morphology of mycoplasmas grown with high concentrations of certain fatty acids, no such changes were noted for $A$. laidlawii $\mathrm{A}$ in these studies with the concentrations and fatty acids tested.

Earlier, we had reported a decrease in the osmotic fragility for Acholeplasma laidlawii A grown with various long-chain cyclopropane and unsaturated fatty acids (Rottem \& Panos, I969). However, maximal membrane stability occurred at concentrations of each fatty acid higher than required for a maximal yield of the organism, i.e. at concentrations somewhat inhibitory for growth. Therefore, our past and present results now show that a correlation exists between fatty acid concentration and yield of $A$. laidlawii A, but that there is no relationship between fatty acid concentration, maximal yield and greatest membrane osmotic stability.

The incorporation of cis-9, I0-methylenehexadecanoic acid, with the derived cis-I I, I 2methyleneoctadecanoic acid, into the membrane polar lipids was similar in magnitude to that of cis-1 I, I2-octadecenoic acid. With cis-9, I0-methylenehexadecanoic acid as growth factor there was an unexpected twofold increase in the amount of tetradecanoic acid found in the membrane polar lipids. At present there is no explanation for this increase, though a similar increase was observed previously when this organism was grown with cis- I I, I 2-methyleneoctadecanoic acid but not with a mixture of cis-I I, I 2-methyleneoctadecanoic plus cis-I I, I 2-octadecenoic acids (Panos \& Rottem, I970).

The cell-free system from Acholeplasma laidlawii A synthesized less cis-1 I, I 2-methyleneoctadecanoic and tetradecanoic acids but more octadecanoic acid, in relative proportions, than did the intact organism. Also, in addition to the formation of eicosanoic acid (Rottem \& Panos, 1970), some continued elongation of cis-9,10-methylenehexadecanoic acid beyond that of cis-1 1, 12-methyleneoctadecanoic acid was indicated using extracts from this organism grown with cis-I I, I 2-methyleneoctadecanoic acid. Therefore, the types and amounts of fatty acids formed depend upon the regulatory mechanism governed by the integrity of the intact organism and the composition of the growth medium. Also, earlier studies had shown this cell-free system to be incapable of forming cyclopropane acids (Rottem \& Panos, 1970). The persistent detection of labelled cis-9, I0-methylenehexadecanoic acid, even when this acid was added as substrate to reaction mixtures with extracts from cells grown with this acid, was therefore of interest. Although not pursued further, this may be indicative of some fatty acid catabolism and resynthesis in this cell-free system as noted in bacteria (Weeks, Shapiro, Burns \& Wakil, I969). 
These investigations were supported by a grant (AI I I I 70-OI) from the National Institute of Allergy and Infectious Diseases, U.S. Public Health Service.

\section{REFERENCES}

Brian, B. L., Gracy, R. W. \& Scholes, V. E. (1972). Gas chromatography of cyclopropane fatty acid methylesters prepared with methanolic boron trichloride and boron trifluoride. Journal of Chromatography 66, $138-140$.

Cohen, M. \& Panos, C. (I966). Membrane lipid composition of Streptococcus pyogenes and derived L-form. Biochemistry 5, 2385-2392.

Dawidowicz, E. A. \& Thompson, T. E. (I97I). Artifacts produced by boron trifluoride methanolysis of a synthetic lecithin containing cyclopropane fatty acids (1-2-dihydrosterculosyl-3-sn-phosphatidylcholine). Journal of Lipid Research 12, 636-637.

Dittmer, J. C. \& Lester, R. L. (1964). A simple, specific spray for the detection of phospholipids on thinlayer chromatograms. Journal of Lipid Research 5, I26-I 27.

Goldfine, H. \& PANOS, C. (1971). Phospholipids of Clostridium butyricum. IV. Analysis of the positional isomers of monounsaturated and cyclopropane fatty acids and alk-I'-enyl ethers by capillary column chromatography. Journal of Lipid Research 12, $214-220$.

Henrikson, C. V. \& Panos, C. (1969). Fatty acid composition, distribution, and requirements of two nonsterol-requiring mycoplasmas from complex but defatted growth media. Biochemistry 8, 646-65I.

Hofmann, K. (1962). Fatty Acid Metabolism in Microorganisms. New York: J. Wiley.

Hofmann, K., Henis, D. B. \& Panos, C. (1957). Fatty acid interconversions in lactobacilli. Journal of Biological Chemistry 228, 349-355.

Hofmann, K., Lucas, R. A. \& Sax, S. M. (1952). The chemical nature of the fatty acids of Lactobacillus arabinosus. Journal of Biological Chemistry 195, 473-485.

Lowry, O. H., Rosebrough, N. J., Farr, A. L. \& Randall, R. J. (I95I). Protein measurement with the Folin reagent. Journal of Biological Chemistry I93, 265-275.

O'Leary, W. M. (1967). The Chemistry and Metabolism of Microbial Lipids. Cleveland: World Publishing.

Panos, C., Cohen, M. \& Fagan, G. ( I 966). Lipid alterations after cell wall inhibition. Fatty acid content of Streptococcus pyogenes and derived L-form. Biochemistry 5, I46I-I 468.

Panos, C. \& Henrikson, C. V. ( 1968). Resolution of positional isomers of bacterial long chain cyclopropanering containing fatty acids by capillary column chromatography. Joumal of Gas Chromatography 6, $55 \mathrm{I}-554$

Panos, C. \& Henrikson, C. V. (Ig69). Fatty acid interconversions in Mycoplasma sp. Khs. Biochemistry 8, $652-658$.

Panos, C. \& Rottem, S. (I 970). Incorporation and elongation of fatty acid isomers by Mycoplasma laidlawii A. Biochemistry 9, 407-412.

RAZIN, S. (I 973). Physiology of Mycoplasmas. Advances of Microbial Physiology 9 (in the Press).

Razin, S., Tourtellotte, M. E., McElhaney, R. N. \& Pollack, J. D. (1966). Influence of lipid components of Mycoplasma laidlawii membranes on osmotic fragility of cells. Journal of Bacteriology $\mathbf{9 r}$, $609-616$

Rottem, S. \& PANos, C. (1969). The effect of long chain fatty acid isomers on growth, fatty acid composition and osmotic fragility of Mycoplasma laidlawii A. Journal of General Microbiology 59, 3I 7-328.

RotTem, S. \& PAnos, C. ( I 970). The synthesis of long-chain fatty acids by a cell-free system from Mycoplasma laidlawii A. Biochemistry 9, 57-63.

Sмiтh, P. F. (1971). The Biology of Mycoplasmas. New York: Academic Press.

Weeks, G., Shapiro, M., Burns, R. O. \& Wakil, S. J. (1969). Control of fatty acid metabolism. I. Induction of the enzymes of fatty acid oxidation in Escherichia coli. Journal of Bacteriology 97, 827-836.

Weinbaum, G. \& Panos, C. (1966). Fatty acid distribution in normal and filamentous Escherichia coli. Journal of Bacteriology 92, I 576-1577. 